ulse is very feeble. She says her bowels are very costive, and, though her menses are regular, there is always severe dysmenorrhoea.

A vaginal examination reveals retroflexion of the uterus, and the rectum loaded with hardened fæces, which are pressing on the fundus of the uterus, and actually tending to hold it in its abnormal position. The womb measures three inches, and its walls are soft and flabby. My impression on making the examination was, that the constantly loaded condition of the rectum was really the cause of the malposition of the organ, as the patient had never been pregnant, and the walls of the uterus were flaccid and therefore more easily bent out of position.

Whilst attending to the uterine ailment, I ordered an enem: of salt and water to be used every alternate day, which gave the greatest possible relief to the patient, and she gained strength so rapidly that at the end of three months she expressed herself as feeling perfectly well.

It would be quite possible to go on quoting cases almost ad infinitum, all of which would demonstrate the baneful effects of constipation; but I trust that the few I have selected will be sufficient to direct the attention of the profession more particularly to this morbid condition, which proves itself not only to be a most distressing disease, but is the superinducing cause of so many other disorders. It will be observed that I have not related any cases of adult males who have been treated by me for this affection, but it is not because there is a paucity of such cases, for although females are much more prone to this disease, and suffer more from it than members of the male sex, yet one often meets with constipation in men which not only itself prodnces a whole host of distressing symptoms, but when allowed to go on unchecked, helps to develop what but for it might still remain latent disease. I do not happen to have notes of such cases, but I can recall to my mind quite a number of instances where constipation was really the cause of great mental depression, irritability of temper, and weakness of body, these all being attributed to want of tone, but which speedily disappeared when enemata were regularly employed to keep the bowels in a state of action.

Glasgow.

\section{CASES OF CONGENITAL HYDROCELE OF THE TESTIS CURED BY ACUPUNCTURE.}

BY SAMUEL OSBORN, F.R.C.S.,

ASSISTANT-SURGEON TO THE SURGICAT APPLIANCE SOCIETY

CASE 1._J. D_, aged six months, has suffered from hydrocele on the right side since birth. He was ordered by a surgeon to wear a truss, and has done so for one month, the last fortnight wearing it night and day. No alteration has occurred in the size, and his mother fancies, if anything, it is somewhat larger. The scrotum is swollen and red from the constant pressure of the truss, which was consequently discontinued, and the scrotum ordered to be bathed twice daily with cold water. The hydrocele is transparent by transmitted light, oval in shape, and gives only a slight impulse on the patient's coughing. There is no alteration in size when the patient is in the recumbent posture.

Jan, 15th. - Swelling and redness have disappeared. The hydrocele was punctured in three places with an ordinary suture needle; the flat-shaped needle after insertion being turned at right angles to the wound of entrance. A small quantity of clear hydrocelic fluid escaped, the greater quantity passing on manipulation into the cellular tissue, external to the tunica vaginalis. The bathing of the scrotum with cold water three times a day to be continued.

16th.-The swelling is much larger than it has ever been, accompanied with much redness, extending up to the navel, and involving the right iliac region and corresponding half of the umbilical region. Cold water application still continued.

17th.-Swelling beginning to go down, and the redness to disappear.

29 th. - Ifydrocele has entirely disappeared.

Feb. 16 th. - No reaccumalation of fluid.

CASE 2.-E. $\mathrm{H}-$, aged two years, made application for a truss, but the child was found to have a hydrocele on the right side, which had only been noticed six weeks previously. Evaporating lotions and cold water had been used for the last six weeks without benefit. Hydrocele is transparent, oval in shape, and gives hardly any impulse on the patient's coughing.

Oct, 26th. - Hydrocele punctured in one place with a broad needle, and about a tablespoonful of perfectly clear fluid withdrawn. Douching of scrotum with cold water ordered several times daily.

Nov. 16th.-Hydrocele is less by two-thirds the size it was previously. Cold douching to be continued.

Dec. 30th. - No sign of liydrocele.

CASE 3.- E. B-, aged nine years, applied to the Surgical Appliance Society for a truss, supposing himself to be ruptured. He was found to be suffering from a congenital hydrocele of the right side, which had been noticed when an infant by his mother, who states that it then looked "puffed like a bladder." The last three months it has altered in character, " becoming larger and more solid." It is now pear-shaped, transparent by transmitted light, and gives a distinct impulse at the neck on the patient's coughing, and is diminished in size on assuming the horizontal posture.

Dec. 10th.-Punctured by an ordinary suture needle in one place, and about a teaspoonful and a half of clear water. like fluid came away. Sac freely manipulated, some of the fluid escaping into the subcutaneous areolar tissue. Patient ordered to lay up in bed for a week, and an ice-bag to be applied to the scrotum, so as to keep up contractility in the muscular dartos.

18th.-No alteration; sac continues empty, as after the tapping.

Jan. 13th.-The mother writes saying, "The swelling has quite disappeared, and the child perfectly well."

Remarles. - These three cases are probably all instances of congenital hydrocele of the testis, the communication with the abdomen in each case being more or less distinct, according to the size of the opening of the funicular process into the peritoneal cavity. They are also all on the right side of the body, this being accounted for by the right funicular portion of the vaginal process of peritoneum being the later of the two in closing; the left testicle descending prior to the right in the majority of instances. It is also noticeable that the fluid in these cases is generally clear, and more like the fluid of the peritoneum than in those cases of hydrocele which are shut off from that cavity.

Maddox-street, $\mathrm{W}$.

\section{FURTHER NOTES ON A CASE OF LEPROSY} ASSOCIATED WITH FILARIA. ${ }^{\prime}$

\section{BY JOSEPH BANCROFT, M.D.}

SINCE my previous account of this case $I$ have seen the patient frequently. I removed a carious phalanx from a finger of the left hand. The finger was extremely painful afterwards, though otherwise anæsthetic. The stump was dipped often in laudanum for relief, after which it healed. The blood that was lost during the operation was collected, diluted with water, and allowed to subside in a conical vessel, but no filariæ were seen either in the blood or in the tissues of the amputated phalanx. I examined blood repeatedly afterwards, taking it from enlarged cutaneous veins of the thigh, the lobe of the ear, and the fingers, with negative results. Bullæ on the fingers have repeatedly formed during this winter; they appear like the results of contact of a hot body, and contain serum and coagulated fibrine, like the jelly blister produced by cartharides. No microscopic peculiarity was noticed in the contents. There are enlargements on the musculo-spiral and median nerves. One of these causes a peculiar thrill when slightly pressed. They are above the elbow, in the neighbourhood in which abscesses form, containing parent worms in the lymphangeitis cases. Patient tells me that the anæsthetic patches on his arms and body keep quite dry when he is visibly perspiring.

About a month ago a bulla formed over the dorsal surface of the last joint of the right forefinger. The bulla burst; an ulcer formed, which penetrated the joint, destroying the extensor tendon; the flexor then drew the phalanx a little 
towards the palm. Much pain was experienced, though to contact the finger was devoid of sensibility. Patient would insist on having the finger removed. I cut through the first phalanx a little above the metacarpal joint. There has been much less pain in the healing of this stump, owing, I imagine, to more diseased surface being removed. All the blood was collected and set aside, but in it no filaria was found. The tissues of the dissected finger gave also negative results, except the diseased scrapings of the joint. In these one filaria was found, which under the $\frac{1}{4}$-inch was seen to coil itself up repeatedly into a spiral of four close rings, after which it suddenly straightened itself. The presence of a worm which fills the field of the $\frac{1}{4}$-inch, and sets all the blond-cells into violent motion, when once seen, does not admit of doubt.

Case 11 of my first series in the Pathological Society's Transactions suffered in June from two abscesses of the arm. I obtained from each, in the matter discharged, a dead parent worm. I searched over much blood before $I$ found a single microscopic filaria. In winter it would seem that embryonic worms are not given off in great numbers.

Brisbane, July, 1879.

\section{A CASE OF FATAL PERITYPHLITIS FROM PERFORATION OF THE VERMIFORM APPENDIX BY AN ORANGE-PIP.}

\section{BY JOHN SERVICE, L.R.C.S. \& L.R.C.P. EDIN.,} SURGEON TO THE BOLDON COLLIERY, NEWCASTLE-ON-TYNE.

THE following case, which occurred in the practice of my friend Dr. Whamond, of Jarrow, whom I was assisting at the time, proves, I think conclusively, that foreign bodies do sometimes perforate the crecal appendix with fatal results.

Sarah Jane P-, of Monkton, in the parish of Jarrow, aged eleven, previously in good health, was suddenly seized on the night of Dec. lst, 1877, with a severe pain in the right iliac region. When seen shortly after, she was lying in bed with the right leg drawn up, an anxious expression on the face, and respiration performed with evident fear. Temperature slightly over normal. The chest sounds were natural ; there was no appearance of spinal disease, no deposit in the urine, and the bowels were unaffected; the tongue was moderately clean, nor did the girl complain of headache or thirst. An opiate was given and a blister applied to the part. Next day her condition was much the same, and the pain, though unaffected by large doses of opium, would yet, seemingly irrespective of any treatment, intermit for as long as three hours at a time. There was now slight fulness and slight percussion-dulness over the seat of pain, but both were very trifling and not constant. Her condition became gradually worse, rapid weak pulse, furred brown tongue, \&c., while the pain extended over the whole abdomen. Death occurred suddenly, with vomiting of black matter, at 9 A.M. on Dec. 14th, thirteen days from the beginning of the illness.

Necropsy, thirty hours after death.-The body was fairly nourished, and of the average size for the age. There were no external marks save that of the blister. The abdomen only was examined. An incision having been made through the linea alba, the peritoneum was found to be inflamed and adherent to the bowels. On section a large quantity of pus welled out from the right iliac fossa, and, together with what was now dipped and sponced ont, would amount to fully a quart. During the removal of the fluid a little greyish-white substance, of about the size and appearance of an orange-pip, was discovered and laid aside for subsequent examination. A large ashy-grey membrane, equal in size to a small saucer, was found attached to the cæcum, and a portion of the same material adherent to the tip of the vermiform appendix, which was perforated and had evidently communicated with the pyogenic membrane referred to. The kidneys and ureters were found to be healthy. We concluded that death had resulted from peritonitis, due to the bursting of a large abscess, which again had been caused by perforation of the crecal appendix by a foreign body impacted there, and a consequent extensive amount of perityphilitic inflammation.

On examining the foreign body found, it had the appearance already described, was soft, and cut readily with a knife. It was insoluble in water cold or lot, insoluble in nitric and in hydrochloric acids, but slightly soluble in nitro. hydrochloric with heat. The solution gave no precipitate with ammonic oxalate nor with hydro-disodic phosphate, proving it to be neither lime nor a phosphate; nor did it effervesce with an acid, showing the absence of a carbonate. On microscopic examination, a section of the substance shoved a distinct fibro-cellular structure mingled with a soft débris. Upon inquiry being made, it was found that the girl's father had brought home some oranges about a week previous to the beginning of her illness, and it was also ascertained that of these she ate one on the 25th of Novem. ber; that was six days before her illness began and nineteen days before death.

That from the presence of glandular elements within the appendix natural secretions may become the nuclei of small calculi, nobody, I think, can doubt; and even fæcal matter, as in the case reported by Dr. Maunsell Collins in TrE LANCER of December 13th, 1879, may occasionally lead to the same result; but, on the other hand, it seems to be equally certain that this trap in the alimentary canal may sometimes catch larger travelling substances, and has often done so, notwithstanding the high authorities quoted by Dr. Collins to the contrary. It would almost seem, indeed, as if popular belief pointed to some salutary lessons of the kind in the past. Who does not remember having been cautioned in childhood against the swallowing of fruitstones, "because they were poison" (as some of course are), or be. cause "a tree would grow up into the throat and produce suffocation"?

West Boldon.

\section{9 望tirtor}

\section{HOSPITAL PRACTICE, BRITISH AND FOREIGN.}

Nulla antem est alia pro certo noscendi via, nisi quamplurimas et morboram et dissectionum historias, tum aliorum, tum proprias collectas habere, et inter se comparare.-MorgagN I De Sed. et Caus. Morb., lib. iv. Procemium.

\section{GUY'S HOSPITAL.}

SURGICAL CASES ILLUSTRATING WOUND TREATMENT AND REPAIR.

(Under the care of Mr. BRYANT.)

THE following cases show that serious wounds may be made and repair take place under a plan of simple dressing, without the occurrence of any important rise of temperature or serious disturbance of the constitutional state.

Recurrent Sarcoma of Breast; Excision; Primary Union. (From notes taken by Mr. C. L. Jones.) - Matilda H-, fifty-one years old, was admitted into Lydia ward on April 30th, 1877. She had been in the hospital in October, 1874, and her right breast was then excised. The wound healed partly by primary intention and partly by granulations. About two years after that operation she noticed the tumour began to grow again at the lower part, and, latterly, had increased very rapidly. When admitted she appeared a fairly healthy-looking woman. There were enlarged veins over the remains of the right breast, and a large transverse scar entirely healed. There was a tumour rather larger than half an orange occupying the situation of the breast; it was irregularly circular in form ; the surface felt irregular, lobulated, not very hard, rather spongy, not adherent to skin or pectoral muscle, and there were no enlarged glands in the axilla.

On May 15th the patient was placed under the infuence of chloroform, and the growth was excised, the edoes of the wound being brought together with sutures. The growth appeared to be a typical sarcoma. There was some sickness after the chloroform, and she liad no sleep. Temperature $101 \cdot 3^{\circ}$; pulse 120 . On the 17 th she had quite recovered from the operation, and the wound seemed to have healed by first intention; temperature $100^{\circ}$, pulse 108 . On the 24 th the wound had liealed, and on the 25th she left the hospital. After the 17 th the temperature never exceeded normal. 